\title{
Study on the Function of Interpersonal Grammatical Metaphor
}

\author{
Gao Song \\ School of Foreign Languages \\ University of Jinan \\ Jinan, China 250022
}

\begin{abstract}
Grammatical metaphor is a language device that can be used in expressing ideas and organizing English texts. By using grammatical metaphor flexibly, people may make their expressions vivid and lively, embodying the image function of language. In consequence, interpersonal grammatical metaphor is quite often used in English advertisement to strengthen the evocative function of discourses and achieve good advertising effect.
\end{abstract} effect

Keywords-interpersonal grammatical metaphor; function;

\section{INTRODUCTION}

Interpersonal grammatical metaphor is an important part of grammatical metaphor theory put forward by famous linguist Halliday [1], it includes metaphors of mood and metaphors of modality. A metaphor of mood is a kind of transfer of mood, indicating a shift from one mood domain to another. For example, people use interrogative mood to realize the command function, this is the usage metaphors of mood. Metaphors of modality means a kind of language phenomenon that people use clauses to replace model verbs and model adverbs to realize the model meaning. Based on the existing researches, this paper conducts exploratory research on the function of interpersonal grammatical.

\section{INTERPERSONAL GRAMMATICAL METAPHOR}

In general, speakers play different speech roles in their communication to realize the speech functions including statements, questions, offerings and orders, and to further realize the purpose of communication. In normal conditions, there are some correspondence between speech function and mood: the function of assertion is usually achieved by indicative mood; the function of question is usually achieved by interrogative mood; and the function of commands and offerings is often achieved by imperative mood. These represent the congruent form of mood. Functional linguistics, however, hold the idea that besides congruent language form, there may exist phenomenon of grammatical metaphor when people choose ways to express moods. Therefore, Halliday [1] put forward the concept of metaphors of mood. As is known to all, the relationship between various language functions and mood system is relatively complex, a function can be reflected by the language form of different moods. For example: (a). (1) You should go to work at once.

(2) Could you go to work at once?

(3) Go to work at once!

It can be seen that the three sentences above are all able to achieve the "command" function of language. The usage of imperative mood in example (3) represents the consistency of the "command" function. However, indicative mood and interrogative mood are respectively exploited in example (1) and example (2). These are common metaphors of mood.

The mood system of language is used to express people's judgment and assessment on things, the system normally includes the modal verbs, model adverbs and the extending part of predicate. That is to say, the model meaning of language is normally achieved by the modal verbs, model adverbs and the extending part of predicate, which is the "congruent form" of moods. To variedly express the modal meaning, one can also flexibly use clauses like "It is likely that, I think that", and these are all metaphoric expressions, that is, metaphors of modality. Examples are as follows: face.

(b). (1) Mary probably knows that accident. Look at her

(2) It's likely that Mary knows that accident. Look at her face.

It can be seen that sentence (1) presents the congruent form, and sentence (2) presents the metaphoric form. Because the modal meaning in sentence (1) showed by the modal adverb "probably", is replaced by the clause "It's likely" in sentence (2). Although the subject and predicate are all equipped, this clause only achieves the function of modal meaning. Then look at the following examples :

(c). (1) You are supposed to go to attend the meeting at ten tomorrow morning.

(2) It is expected that you go to attend the meeting at ten tomorrow morning.

Sentence (1) presents the congruent form, and sentence (2) presents the metaphoric form. It can be seen that the modal meaning in sentence (1) showed by the extending part of the predicate "supposed to", is achieved by the clause "It is expected". The same as the above clause "It's likely", 
though the subject and predicate are all equipped, this clause only achieves the modal meaning suggesting responsibility.

\section{FUNCTIONS OF INTERPERSONAL GRAMMATICAL METAPHOR}

The Functions of Interpersonal Grammatical Metaphor can be showed in the following three aspects:

\section{A. The Social Function of Interpersonal Grammatical Metaphor}

Most time in social life, interpersonal grammatical metaphor is often used as euphemistic expressions to show more politeness to reach certain communicative purpose. It can be said that the interpersonal grammatical metaphor is used in communication for euphemism and politeness. The proper usage of interpersonal grammatical metaphor is helpful to create harmonious atmosphere, maintain friendly communicative state, and ensure that the self-pride of the listener will not be hurt and the communication will be fluently conducted [2]. Examples are as follows:

(d). A: There is an important conference next Monday. I have to prepare all the materials about it, but I am so busy now. I need some help.

B: I would love to help you. I've just finished my work.

In this example, Speaker A chooses indicative mood "I need some help" to politely achieve the function of asking B for help. The congruent form should be "Can you do me a favor?", and this example belongs to metaphors of mood. It can be seen that the use of metaphors of mood enables the fluent communication between two sides and greatly strengthen the politeness, therefore not only maintaining the self-pride of two people, but also achieving the communicative purpose.

As is known to all, there are various factors lead to different language forms of the speaker, including the social role of the speaker, attitudes toward each other, the power relationship between the two sides and the degree of familiarity. Therefore, flexible use of metaphors of mood could help us take these factors into consideration during the communication, and also enable us to better understand the meaning of the other's words and make proper judgment on specific linguistic environment. These are all because metaphors of mood cover a large scale of semantic connotation. In fact, metaphors of modality have the same functions. See example (f):

(f). Manager: An important leader will inspect our company tomorrow. This is a good opportunity for the development of our company. So it is required that all the people do their jobs well tomorrow.

\section{Employees: Ok.}

It can be seen that during this conversation, the manager use the sentence "it is required that all the people do their jobs well tomorrow" which contains metaphors of modality, so that his personal attitudes is "impersonalized", and the origin of orders is blurred. This is a kind of explicit and objective modality orientation, which is metaphorical. It can make the assertion or order of the speaker more objective, so as to hide the real origin of the modality, avoid the responsibility as the one sending orders and make his employees hard to raise an objection to the order.

Another language form of metaphors of modality is explicit but subjective modality orientation, which means to use clauses like "I think", "I believe" to present modality. In real conversation among people, sometimes the speaker may deliberately use this kind of explicit and subjective metaphorical form to emphasize the uncertainty in his or her views on things. And under normal conditions, such modality orientation can reflect the social status, power relationship and degree of familiarity of both sides of the conversation. For instance, people often use such kind of metaphorical sentences when they put forward different ideas from strangers or those who are in higher positions, so as to show respect to the other person. See example $(\mathrm{g})$ :

(g). John has made some mistakes in his work, but he has also tried to do better. So taking his youth into account I think that may be acceptable.

In this example, the speaker selects the explicit and subjective sentence pattern "I think that may be acceptable" to show his or her uncertainty in views. In this way, he or she not only express the thoughts, but also show the respect to others, suggesting that this clause is a proper metaphorical expression.

\section{B. The Textual Function of Interpersonal Grammatical Metaphor}

Widdowson [3] thinks that the construction of discourse is jointly conducted during the interaction between participants from two sides. The discourse, no matter conversational one or written one, is an interaction required the participation of both sides. The participant of interaction not only covers the two sides involved in the conversation, but also the writer and the reader of the written discourse. During the process of interaction, the participants can flexibly use various language forms to express their inner thoughts, then further construct different discourses, effectively convey the meaning and push the smooth communication. Scholars like Zhu Yongsheng [4] pointed out that discourses are concrete forms of manifestation, and are real examples of language communication involving people's participation. Researches show that interpersonal grammatical metaphor, as an important language form, owns great textual value and function for it is quite helpful to convey the meaning, construct coherent and smooth discourses. See example (h):

(h). Engelbreit is cheerful, down-to-earth, humorous, and always cute. "I think the world could use more cuteness," she explains. Indeed, it's her trademark. Her business card once featured a drawing of Ann Estelle, cigar in her mouth and drink in hand, with the message "Engelbreit's the Name, Cute Is My Game.”

In this example, the use of the clause "I think the world could use more cuteness" which contains metaphors of 
modality leads to the coherent discourse. This kind of sentence pattern with explicit and subjective modality orientation highlights that Engelbreit's enthusiasm for life and those lovely things. The theme - Engelbreit, same in former three clauses in this discourse, is really coherent.

As is known to all, an effective conversation means a smooth exchange of information during which the speaker alternatively make statements, ask and reply. Therefore, both sides of the dialogue continuously define the limit of the conversational turn, shift topic in proper time to promote the interaction between them and ensure the fluent communication. In this respect, the use of interpersonal grammatical metaphor makes a real difference. This is because in real dialogue, flexible use of interpersonal grammatical metaphor can push the shift of conversational turn between speakers so that the discourse can be smoothly conducted. See example (i):

(i). A: Lucy will participate in the contest next week. Do you think if she will have a chance to get the first prize?

B: I believe that Lucy is a clever girl and she is very diligent in her work, so it is very likely that she will win the competition.

A: Ok. I also think that Lucy will have an opportunity to succeed in this contest. We should believe in this girl because she has never let us down.

In this short dialogue, the two people both properly make use of sentences containing metaphors of modality. There are sentences with explicit and subjective modality orientation like "I believe", "I also think", as well as sentences with explicit and objective modality orientation such as "it is very likely" in the above example. Sentences with such modality orientation promote the shift of conversational turn between the two speakers, which enables them to fully exchange information and conduct dialogue.

\section{The Advertising Function of Interpersonal Grammatical Metaphor}

Advertisement, which is commonly seen in modern society, plays an very important role in people's daily life. The purpose of advertising discourse is not only for tell people the relevant information, but also for moving people's heart to let them accept those companies' advertising concept and further buy their products. In fact, interpersonal grammatical metaphor is often exploited in advertisement to strengthen the evocative function of the discourse and raise people's trust in the related products. See example (i):

(i). Suppose we increase your productivity and cut your printing costs? (Ricoh Company)

Example (i) is an advertisement of printing machine from Ricoh Company. The interrogative mood is used in this advertisement not for inquiry, but for reminding people of the high quality of the printing machine: high "printing productivity" and low "printing costs". It can be seen that the flexible use of metaphors of modality make the advertisement possible to stimulate people's wish to raise the printing productivity and lower the printing costs. In this way, the advertisement successfully attracts customers to buy this printing machine.

(j). At Toyota, we believe that real quality comes from careful creation, as well as technical expertise. (丰田汽车)

In can be seen that this advertisement use the sentence pattern (we believe) with explicit and subjective modality orientation, highlighting that Toyota Motor Corporation is really care about the quality of its products and satisfying consumers' psychological needs for high-quality cars. Researches show that the proper use of such sentence pattern can make the ideas in advertisement more subjective, enrich them with more emotional coloring. As a result, the advertisement can be more reliable and convincing for those consumers, further promote the sales of a company.

\section{CONCLUSION}

Interpersonal grammatical metaphor is an essential linguistic means with certain social function, textual function and advertising function. Proper use of interpersonal grammatical metaphor is beneficial to create harmonious atmosphere, maintain friendly communicative state and ensure the smooth interaction. In many discourses, interpersonal grammatical metaphor owns great textual value because it is quite helpful to convey the meaning, construct coherent and smooth discourses. In consequence, interpersonal grammatical metaphor is quite often used in English advertisement to strengthen the evocative function of discourses and achieve good advertising effect.

\section{REFERENCES}

[1] Halliday, M. A. K. An Introduction to Functional Grammar [M]. London: Edward Arnold, 1994.

[2] Zhang Chenguang. Interpersonal Grammatical Metaphor in English [J]. Foreign Languages and Their Teaching, 2001, (7): 6-8.

[3] Yan Shiqing. The Development of the Grammatical Metaphor Theory and Its Theoretical Implications [J]. Journal of Foreign Languages, 2003, (3): 51-57.

[4] Qin Dejuan. A Comparative Study of Grammatical Metaphor and Cognitive Metaphor [J]. Foreign Language Research, 2008, (2): 135139.

[5] Ma Yuxia. Exploration on Relations of Textual Metaphor in English [J]. Science \& Technology Information, 2010, (25): 659-660.

[6] Thompson, G. Introducing Functional Grammar (2nd Edition) [M]. London: Amold, 2004.

[7] Ming Yushan \& Zhen Qiang. An Analysis of Hero and Heroin in Jane Eyre from the Perspective of Interpersonal Grammatical Metaphor [J] Journey of Liaoning Technical University, 2017, (1): 84-88.

[8] Lei Min. Analysis of Interpersonal Grammatical Metaphor in English Advertisement [J]. J. Changchun Inst. Tech, 2011, (4): 108-111.

[9] Yang Yufang. Pragmatic Research of English Requests from the Perspective of Grammatical Metaphor Theory [J]. Journal of North University of China, 2017, (3): 76-79.

[10] Lin Zhengjun \& Dong Xiaoming. The Metonymic Attribute of Grammatical Metaphor [J]. Journal of Northeast Normal University, 2017, (4): 7- 12. 